\title{
The Effect of non-Thermal Processing Technologies on Microbial Inactivation: An Investigation into sub-Lethal Injury of Escherichia Coli and Pseudomonas Fluorescens
}

\author{
Rachel Halpin \\ Technological University Dublin, rachel.halpin@tudublin.ie \\ L. Duffy \\ School of Biomolecular and Biomedical Sciences, University College Dublin, \\ O. Cregenzán-Alberti, \\ School of Biomolecular and Biomedical Sciences, University College Dublin,
}

See next page for additional authors

Follow this and additional works at: https://arrow.tudublin.ie/schfsehart

Part of the Food Biotechnology Commons, Food Chemistry Commons, Food Microbiology Commons, and the Food Processing Commons

\section{Recommended Citation}

Halpin, R. (2014)The Effect of non-Thermal Processing Technologies on Microbial Inactivation: An Investigation into sub-Lethal Injury of Escherichia Coli and Pseudomonas Fluorescens, Food Control,Volume 41, July 2014, Pages 106-115. DOI:10.1016/j.foodcont.2014.01.011

This Article is brought to you for free and open access by the School of Food Science and Environmental Health at ARROW@TU Dublin. It has been accepted for inclusion in Articles by an authorized administrator of ARROW@TU Dublin. For more information, please contact arrow.admin@tudublin.ie, aisling.coyne@tudublin.ie, gerard.connolly@tudublin.ie.

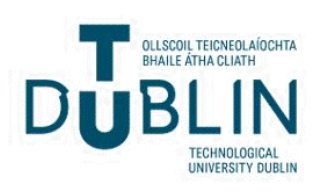




\section{Authors}

Rachel Halpin; L. Duffy; O. Cregenzán-Alberti,; J.G Lyng; and F. Noci

This article is available at ARROW@TU Dublin: https://arrow.tudublin.ie/schfsehart/245 


\section{The effect of non-thermal processing technologies}

2 on microbial inactivation: An investigation into

3 sub-lethal injury of Escherichia coli and

$4 \quad$ Pseudomonas fluorescens

5 Halpin, R.M. ${ }^{1}{ }^{*}$, Duffy, L., Cregenzán-Alberti, O. ${ }^{1}$, Lyng, J.G. ${ }^{1}$ and Noci, F $^{2}$.

$6 \quad{ }^{1}$ School of Agriculture and Food Science, University College Dublin, Ireland

$7 \quad{ }^{2}$ Galway Mayo Institute of Technology, Galway, Ireland.

8

9

$10 *$ Corresponding author: Dr. Rachel Halpin.

11 Postal address: School of Agriculture and Food Science, University College Dublin,

12 Belfield, Dublin 4, Ireland.

13 Tel No.: 0035317167711

14 E-mail: rachel.halpin@ucd.ie

15 


\section{Abstract}

25 In recent years, there has been an increased interest in food processing technologies that

26 could lessen the thermal impact on food products. In the present study, thermosonication

27 (TS) and pulsed electric fields (PEF), applied individually or in combination (TS/PEF),

28 were investigated to determine their effects on inactivation and sub-lethal injury of

29 Pseudomonas fluorescens and Escherichia coli. TS was applied at a low (L) and high

$30 \quad(\mathrm{H})$ wave amplitude (L; $18.6 \mu \mathrm{m}, \mathrm{H} ; 27.9 \mu \mathrm{m}$, respectively), while PEF was applied at a

31 low and high electrical field strength $\left(\mathrm{L} ; 29 \mathrm{kVcm}^{-1}, \mathrm{H} ; 32 \mathrm{kVcm}^{-1}\right.$, respectively). In

32 addition, the inhibitory effects of TS/PEF combined were assessed. For P. fluorescens,

33 when applied individually, TS and PEF resulted in $\leq 9 \%$ and $\leq 47 \%$ inactivation,

34 respectively, with $8 \%$ sub-lethal injury following PEF treatment. However, TS/PEF

35 treatment caused $\leq 48 \%$ inactivation and $\leq 34 \%$ sub-lethal injury, respectively. For $E$.

36 coli, TS caused $\leq 6 \%$ inactivation, and $\leq 2 \%$ sub-lethal injury, while PEF treatment alone

37 caused inactivation and sub-lethal injury of $86 \%$ and $29 \%$, respectively. TS/PEF caused

38 a maximum of $66 \%$ inactivation, while sub-lethally injuring approximately $26 \%$ of the

39 of E. coli population. The present study confirms the ability of TS and PEF to inactivate

40 microorganisms, but shows that some bacteria were not killed, but sub-lethally injured.

42 Keywords: Thermosonication, PEF, Escherichia coli, Pseudomonas fluorescens, sub43 lethal injury. 
51 Foods are not sterile substances and microbial spoilage in food is a reality that is

52 perhaps unavoidable. According to Raso et al. (2005), the two main contributors to food

53 spoilage are microorganisms and enzymes in food. There are ample ways of delaying

54 this spoilage process, with the most common method of microbial inactivation being by

55 thermal treatment, or pasteurisation (Raso et al., 2005). Although thermal treatment may

56 effectively kill microorganisms, it can also have damaging effects on the food/beverage.

57 Thus, in recent years there has been considerable interest in food preservation by non-

58 thermal technologies. Some examples of non-thermal technologies include ultrasound

59 (US), high voltage pulsed electric fields (PEF), high intensity light pulses (HILP) and

60 ultraviolet light (UV) (Caminiti et al., 2011). Ultrasound and PEF are two methods of

61 particular interest to the present study.

62 Ultrasound is a novel technology that produces sonic waves with frequencies of

63 16-20 kHz; this is above the upper limit of human hearing (Condón et al., 2005).

64 Ultrasound operates on the mechanism of liquids coming into contact with sonic waves.

65 As these sonic waves penetrate into a liquid medium they create compression and

66 expansion cycles. The expansion cycle creates negative pressure in the liquid. Minute

67 bubbles can be formed when this negative pressure is minimal enough to surpass

68 intermolecular forces. These bubbles expand and contract throughout compression and

69 expansion cycles in a process known as cavitation (Condón et al., 2005). The size of the

70 bubble fluctuates when the ultrasound wave comes into contact with a liquid, and with

71 each new cycle the size of the bubble increases. After alternating cycles of compression

72 and expansion, the sonic energy is no longer able to maintain the vapour phase inside of

73 the bubble and it implodes. The mechanism of microbial inactivation following

74 treatment with ultrasound is that when these bubble implode, it causes the surrounding

75 molecules to collide somewhat powerfully into one another, creating areas of extremely 
76 high temperatures of up to $5500^{\circ} \mathrm{C}$ (Condón et al., 2005). In addition, when these

77 bubbles implode they release shock waves that damage cell membranes, and also may

78 produce free radicals that could potentially contribute to microbial inactivation

79 (Piyasena et al., 2003). It has been suggested that a mild application of heat when used

80 in conjunction with ultrasonication may lead to an increase in the microbial inactivation

81 capacity of US; a process known as thermosonication (TS). Ultrasound can also be

82 combined with pressure, referred to as manosonication, or pressure and heat

83 simultaneously, known as manothermosonication (Piyasena et al., 2003).

84 The second non-thermal method relevant to this study is PEF. Microbial

85 inactivation due to PEF treatment is believed to be caused by disruption of the cell

86 membrane; a process known as ‘electroporation’ (Hamilton and Sale, 1967), which

87 results from recurring application of short pulses of high intensity electric fields

88 (Barbosa-Cánovas \& Sepúlveda, 2005). Electroporation is, essentially the formation of

89 pores in the bacterial membrane, which results in the leakage of intercellular material

90 out of the cell due to an increase in permeability. The degree of microbial inactivation is

91 impacted, among other factors, by the strength of the electrical field applied, the pulse

92 duration and the dimensions of the microbe, including the shape (Barbosa-Cánovas \&

93 Sepúlveda, 2005). The characteristic feature of PEF is that low heat conditions are

94 applied, which makes it highly desirable for heat-sensitive foods and beverages

95 (Barbosa-Cánovas \& Sepúlveda, 2005).

96 Studies have shown that US (Condón et al., 2005) and PEF (Barbosa-Cánovas \&

97 Sepúlveda, 2005) can cause microbial inactivation. However, some microorganisms

98 believed to be "killed" may only be sub-lethally injured. Microbial injury can be

99 defined as a microorganism that has suffered some form of stress but that has the

100 potential to regain viability and to form a colony under the right conditions (Wu, 2008).

101 Injured cells pose quite a threat to food integrity as they are unpredictable and have the 
102 potential to become viable under favourable environmental conditions ( $\mathrm{Wu}, 2008$ ).

103 There has been some controversy as to whether non-thermal technologies such as PEF

104 and US have an "all or nothing” effect, or whether some microbes may simply be sub-

105 lethally injured with the potential to become viable under optimal conditions (Jaeger et

106 al., 2009). It is believed that after treatments, by either thermal or non-thermal

107 technologies, there may be one population of microbes which are dead, another

108 population that are viable, and a third population that are sub-lethally injured $(\mathrm{Wu}$,

109 2008). It is of the utmost importance to be able to distinguish between viable cells and

110 impaired cells in order to gain complete food safety (Wu, 2008).

111 Some examples of spoilage microorganisms commonly found in beverages such

112 as milk, smoothies and fruit juices include Salmonella (Ross et al., 2003), Listeria

113 innocua (Black et al., 2005), Pseudomonas fluorescens (Barsotti \& Cheftel, 1999) and

114 Escherichia coli (Walkling-Ribeiro et al., 2008). In the present study, the main focus

115 was on $P$. fluorescens and E. coli. P. fluorescens is a Gram-negative microorganism, and

116 is regarded as one of the most common psychrotrophic bacteria dominating raw or

117 pasteurised milk at the time of spoilage (Sillankorva et al., 2008). E. coli is also a Gram

118 negative facultative aerobe that is known to contaminate milk and cause spoilage

119 (Awuah et al., 2005). This species has numerous pathogenic varieties which can inhabit

120 the intestinal tract of humans and animals (Dobrindt, 2005).

121 The objective of the present study was to investigate the effect of TS, the effect

122 of PEF and the effect of TS and PEF in combination (i.e. TS/PEF) on microbial

123 inactivation. In addition, the levels of microbial inactivation caused by these non-

124 thermal technologies were compared to those resulting from conventional 125 pasteurisation. A second objective was to determine the levels of sub-lethal injury of $P$. 126 fluorescens and E. coli following these treatments. 


\section{Materials and Methods}

129 2.1. Bacterial isolates and growth conditions

130 Experiments were conducted using E. coli K12 (DSM 1607) and P. fluorescens (NCTC 131 10038) to determine the effects of the chosen non-thermal technologies on (i) microbial

132 inactivation and (ii) sub-lethal injury of these microorganisms. The E. coli culture was 133 obtained from the German Collection of Microorganisms and Cell Cultures (DSMZ,

134 Braun-schweig, Germany) and P. fluorescens was obtained from the National Collection 135 of Type Cultures (NCTC; Public Health Laboratory Service, London, U.K.). Both E. 136 coli and $P$. fluorescens strains were initially grown on tryptone soya agar (TSA; Oxoid, 137 Basingstoke, Hampshire, UK). Following this, a single colony from the relevant agar 138 plate was used to inoculate 1L of brain heart infusion broth (BHI; Oxoid, Basingstoke, 139 Hampshire, UK). Cultures of E. coli or P. fluorescens were incubated for $18 \mathrm{~h}$ at $37^{\circ} \mathrm{C}$ 140 or $30^{\circ} \mathrm{C}$, respectively. Bacterial cells were sedimented by centrifugation at $6153 \times g$ for $14110 \mathrm{~min}$, and pellets were resuspended in Ringer's solution (Oxoid, Basingstoke, 142 Hampshire, UK). Bacterial suspensions were left to stand at room temperature for at 143 least 20 min prior to being subjected to any thermal/ non-thermal treatments.

\section{2.2. Treatment with Thermosonication}

146 A peristaltic pump (Masterflex ${ }^{\circledR}$ L/S ${ }^{\circledR}$, Model No. 77250-62, Cole-Parmer 147 Instrumental Company, IL, USA) was used to pass the bacterial suspension through the 148 TS system at a fixed flow of $160 \mathrm{ml} / \mathrm{min}$. In order to preheat the samples before 149 sonication, the suspension was pumped through a coil immersed in a heated water bath 150 until the temperature at the inlet of the sonication chamber reached $55^{\circ} \mathrm{C}$. The 151 suspension was then sonicated using two ultrasonic processors (Model No. UIP 1000hd,

152 Hielscher, Germany). These sonicators were connected in a row, and had an operational 153 frequency of $20 \mathrm{kHz}$ (Figure 1a). Two sonotrodes (Model No. BS2d40, Hielscher) 
154 which had a $40 \mathrm{~mm}$ frontal face diameter were used. Also, boosters were used to

155 increase the amplitude (Model No. B2-1.8, Hielscher). Sonication was applied at two

156 energy inputs, resulting from varying the amplitude: low (TS-L; $19 \mu \mathrm{m})$ or high (TS-H;

$15728 \mu \mathrm{m}$ ), with the average residence time being c. $2.1 \mathrm{~min}$. The temperature within the

158 chamber was maintained at $55^{\circ} \mathrm{C}$, and overheating of the bacterial suspension during

159 sonication was prevented by water cooling of the treatment chamber. Temperature was

160 monitored using T-type thermocouples and a data logger (Model No. SQ2020, Grant

161 Instruments, Cambridge, UK). A sample of bacterial suspension post-treatment with TS

162 was collected and stored on ice until serial dilutions were prepared (within 1 h)..

\section{2.3. Treatment with Pulsed Electric Field}

165 As described earlier for treatment with TS, the bacterial suspension was pumped into

166 the PEF treatment chamber at a fixed flow rate of $160 \mathrm{ml} / \mathrm{min}$. A lab scale customized

167 system (ELCRACK HVP 5, DIL, German Institute of Food Technologies,

168 Quackenbruck, Germany) was used. The treatment module consisted of three co-linear

169 treatment chambers with integrated refrigerated cooling modules. Each chamber held

170 two co-linear stainless steel electrodes separated by a $5 \mathrm{~mm}$ gap, with the electrode

171 diameter being $3 \mathrm{~mm}$; which resulted in a total treatment volume of $0.106 \mathrm{~cm}^{3}$. The

172 system was monitored using a digital oscilloscope (TDS 2012, Tektronix, Beaverton,

173 OR, USA). The product temperature was recorded with thermocouples (Testo 925, type-

174 K probe, Testo AG, Lenzkirch, Germany) at three locations; before and after the

175 treatment module and immediately before being collected (Figure $1 \mathrm{~b}$ ). Two power

176 levels were applied by varying the electrical field strength; low (PEF-L; 29kVcm${ }^{-1}$ ) and

177 high (PEF-H; 32kVcm$\left.{ }^{-1}\right)$. The PEF system was operated at a constant frequency of 320

$178 \mathrm{~Hz}$, and a pulse width of $10 \mu \mathrm{s}$. It was ensured that the temperature of the bacterial

179 suspension at the inlet of the PEF system was kept below $40^{\circ} \mathrm{C}$. A sample of bacterial 
suspension post-treatment was taken and stored on ice until required.

\section{$182 \quad$ 2.4. TS/PEF processing (combined treatment)}

183 After the bacterial suspension was preheated to $55^{\circ} \mathrm{C}$, it was pumped into the sonicators 184 and treated with $\mathrm{L}$ or $\mathrm{H}(19 \mu \mathrm{m}$ or $28 \mu \mathrm{m}$, respectively) energy inputs. The suspension 185 was then immediately passed into the PEF system where again it was treated with either 186 low $\left(29 \mathrm{kVcm}^{-1}\right)$ or high $\left(32 \mathrm{kVcm}^{-1}\right)$ electrical field strength. Treatments where TS and 187 PEF were combined (i.e. TS/PEF) were referred to as LL (TS=19 $\mu \mathrm{m}, \mathrm{PEF}=29 \mathrm{kVcm}^{-1}$ ), $188 \mathrm{LH}\left(\mathrm{TS}=19 \mu \mathrm{m}, \mathrm{PEF}=32 \mathrm{kVcm}^{-1}\right), \mathrm{HL}\left(\mathrm{TS}=28 \mu \mathrm{m}, \mathrm{PEF}=29 \mathrm{kVcm}^{-1}\right)$ or $\mathrm{HH}(\mathrm{TS}=28$

$189 \mu \mathrm{m}, \mathrm{PEF}=32 \mathrm{kVcm}^{-1}$ ). The bacterial suspension was passed through both systems and a 190 sample was collected and stored on ice until required.

\section{2.5. Thermal Treatment}

193 A tubular heat exchanger (Model No. FT74T, Armfield, Ringwood, UK) was used for 194 pasteurisation of the bacterial suspension. The suspension was heated at $72^{\circ} \mathrm{C}$ for $20 \mathrm{~s}$. 195 An attached cooling system ensured the temperature of the liquid was below $10^{\circ} \mathrm{C}$ after 196 treatment. A sample was taken and stored on ice until required.

\subsection{Enumeration of viable and injured cells}

199 Firstly, a sample of the untreated bacterial suspension was collected and the number of 200 colony forming units per $\mathrm{ml}(\mathrm{CFU} / \mathrm{ml})$ were determined, for the initial working culture 201 (i.e. CFU/ml of initial sample, denoted as 'A' in Equation (3)). This was achieved by 202 preparing decimal dilutions in $9 \mathrm{ml}$ volumes of Ringer's solution. Aliquots $(100 \mu \mathrm{l})$ of 203 these dilutions were plated on TSA plates (in duplicate), and incubated at the 204 appropriate temperature; $37^{\circ} \mathrm{C}$ for $E$. coli, $30^{\circ} \mathrm{C}$ for $P$. fluorescens. To determine the 205 microbial kill due to non-thermal processing by individual or combined methods (i.e. 
TS and/or PEF), a survival fraction study was performed. The number of surviving cells

207 post-processing was determined, and denoted by ' $\mathrm{B}$ ' in Equation (3), which was

208 subsequently used to determine the percentage of microbial inactivation:

209

$$
\mathrm{CFU} / \mathrm{ml} \text { of initial culture }=\mathrm{A}
$$

$$
\% \text { Inactivation }=(1-(B / A)) \times 100
$$

To define the levels of sub-lethal injury (if any), appropriate dilutions of the processed bacterial suspensions were plated onto TSA agar plates containing sodium

216 chloride (TSA+SC; SC: Oxoid, Basingstoke, Hampshire, UK) and incubated for 72 h.

217 These TSA+SC plates were supplemented with 3\% $\mathrm{NaCl}$ (referred to as the 'selective 218 media') in accordance with the method described by Perni et al. (2007). In order to 219 determine the percentage sub-lethal injury (SLI), Equation (6) was used, according to 220 the method of Uyttendaele et al. (2008) and Zhao et al. (2013). Samples of the initial 221 culture were plated on regular TSA plates without any sodium chloride added (referred 222 to as the 'non-selective' media); denoted by ' $C$ ' in Equation (6). The $C F U / m l$ 223 determined from both selective and non-selective media were compared, in order to 224 determine the SLI (refer to Equation (6)).

$$
\mathrm{CFU} / \mathrm{ml} \text { of sub-lethally injured cells }=\mathrm{D}
$$

$$
\% \mathrm{SLI}=(1-(\mathrm{D} / \mathrm{C})) \times 100
$$

230 The CFU/ml determined from both selective and non-selective media were compared, in 231 order to determine the SLI (refer to Equation(6)). Processed samples were plated onto 
232 four agar plates in total (2×TSA and $2 \times \mathrm{TSA}+\mathrm{SC})$ which were incubated for $24 \mathrm{~h}$ and 72

233 h, respectively, to determine microbial inactivation and SLI.

235 2.6.1. Bacterial growth monitoring using optical density (E. coli only)

236 In addition to the plating technique described in section 2.6, sub-lethal injury was also 237 assessed using an optical density based method. Bacterial growth assays were carried 238 out in sterile 96 well plates (Sarstedt, Numbrecht, Germany). Aliquots (100 $\mu$ l) of BHI

239 broth were pipetted into appropriate wells of the 96 well plate. Bacterial suspensions 240 collected from the initial working culture (as a control) and the processed samples were 241 pipetted in $50 \mu \mathrm{l}$ aliquots into the appropriate wells. The plate was then incubated at $24237^{\circ} \mathrm{C}$ for $18 \mathrm{~h}$ in a Multiskan Ascent plate reader (Thermo Electron Corporation, Vantaa, 243 Finland). Optical density (OD) measurements were taken at hourly intervals 244 (wavelength of $590 \mathrm{~nm}$ ), and growth curves were plotted from the OD values using 245 Microsoft Excel $^{\mathrm{TM}}$ (Microsoft Corporation, 2007). In addition, a standard curve of $246 \mathrm{CFU} / \mathrm{ml}$ versus $\mathrm{OD}_{590}$ was prepared for $E$. coli (data not shown). It was determined that 247 an $\mathrm{OD}_{590}$ value of 0.2 corresponded to $c .6 .1 \times 10^{8} \mathrm{CFU} / \mathrm{ml}$.

249 2.7. Statistical Analysis

250 Results were expressed as the mean \pm standard deviation (S.D). Differences between

251 treatments were determined using the least significant difference (L.S.D) function of 252 SAS version 9.1 (SAS Institute, Cary, NC). Data was considered significantly different 253 if $P<0.05$.

\section{Results and Discussion}

256 The average initial concentration of microorganisms in each working culture was 257 determined to be c. $8.6 \times 10^{8}$ and $6.07 \times 10^{8}$ for $P$. fluorescens and E. coli, respectively. 
259 3.1. Effect of TS processing on microbial viability

260 The results for inactivation and SLI of $P$. fluorescens following treatment with

261 TS and thermal pasteurisation are shown in Figure 2(a). Only a small percentage of

262 inactivation was observed following treatment with TS; 9.2\% and 6.4\% inactivation at

263 TS-L $(19 \mu \mathrm{m})$ and TS-H $(28 \mu \mathrm{m})$ power settings, respectively. No significant

264 differences in inactivation levels due to TS were observed between these power settings

$265(P>0.05)$, while pasteurisation resulted in complete inactivation of $P$. fluorescens.

266 In terms of SLI, no injured cells were detected following treatment with TS at

267 either power setting. Therefore, it can be suggested that the population inactivated by

268 TS remained 'dead', and the population that was viable stayed this way. It has been

269 reported previously that when treatment time with ultrasonication (temperature $39 \pm$

$270 \quad 0.3^{\circ} \mathrm{C}$ ) is increased, the destruction of bacteria such as Pseudomonas aeruginosa is also

271 increased (Scherba et al., 1991). There is a limited amount of literature regarding the

272 effects of non-thermal technologies on the viability of $P$. fluorescens following

273 treatment with TS. Thus, very few published studies can be directly compared to the

274 present study. For example, the study by Scherba et al. (1991) discussed the reduction in

275 viability of $P$. fluorescens due to treatment with ultrasound some time ago. In addition, a

276 study by Villamiel and de Jong (2000) examined the inactivation of $P$. fluorescens by

277 ultrasound. However, in recent years the focus of research on inactivation of

278 Pseudomonas by ultrasound technology has shifted towards destruction of this

279 microorganism in biofilms (Xu et al., 2012) and disinfection of instruments used for

280 medical procedures (Jatzwauk et al., 2001). A search for literature specifically

281 discussing inactivation of Pseudomonas by non-thermal technologies does not yield

282 many results, with the main publication found being a study by Shamsi, Versteeg,

283 Sherkat and Wan (1997) which evaluated inactivation by PEF. For future studies 
284 employing ultrasonication, certain parameters (e.g. residence time) could be increased

285 to examine whether a greater level of inactivation of $P$. fluorescens may be achievable.

286 The effects of TS on the viability of E. coli are presented in Figure 2(b). Low

287 levels of inactivation were recorded at both power settings; 1.1\% (TS-L) and 6.3\% (TS-

$288 \mathrm{H}$ ). Minor (yet significant, $P<0.05$ ) differences in inactivation were recorded at different

289 power outputs. It could be suggested that E. coli has a higher resistance to TS

290 processing, as less inactivation was observed for this microorganism than for $P$.

291 fluorescens following treatment with TS. No SLI was observed at the high energy input

$292(28 \mu \mathrm{m})$, but 1.5\% was observed at the low energy input (19 $\mu \mathrm{m})$ (Figure 2(b)).

293 However, these results for SLI of E. coli following TS-H and TS-L were not

294 significantly different from each other $(P>0.05)$.

295 In a review by Scherba et al. (1991) it was reported that when analysed in an 296 aqueous medium using a frequency of $24 \mathrm{kHz}$, the intensity of TS did not affect the 297 level of inactivation of E. coli, and that results remained similar for all intensities used.

298 This observation is in contrast to the results shown in Figure 2(b), as there was a 299 significant difference observed between low and high power outputs $(P<0.05)$. This 300 author also reported that significant reductions in viable populations were achieved with 301 an increase in residence time (Scherba et al., 1991). Limaye and Coakley (1998) 302 suggested that the initial temperature of the bacterial suspension can have significant 303 effects on the survival of E. coli. It was reported that heating to an initial temperature of $30432^{\circ} \mathrm{C}$ resulted in a $99 \%$ reduction of $E$. coli, whereas heating at $17^{\circ} \mathrm{C}$ resulted in a $62 \%$ 305 reduction. In the present investigation, greater inactivation levels may have been 306 obtained if longer residence times or greater power settings had been used.

307 From the results of the present study, it is difficult to visualise a future for this 308 technology used alone for microbial inactivation, as under the experimental conditions 309 used in the present study, relatively low inactivation levels were achieved for E. coli and 
311 potential to be more successful in terms of microbial inactivation than TS used alone,

312 and may offer a solution to the partial success of treatment with ultrasound (Condón et

313 al., 2005). An investigation carried out by Noci, Walking-Ribeiro, Cronin, Morgan and

314 Lyng (2009) suggested that thermosonication may be more useful as a hurdle within a

315 system, instead of a stand-alone method for microbial inactivation in foods and

316 beverages.

3173.2 Effect of PEF processing on microbial viability

318 The levels of microbial inactivation following PEF processing (Figures 3(a) and 3(b))

319 were found to be substantially greater than those resulting from treatment with TS. In

320 the case of $P$. fluorescens, a $26.4 \%$ inactivation was reported at the low power output

$321\left(28 \mathrm{kVcm}^{-1}\right)$, and a significantly greater $(P<0.05)$ inactivation of $47.1 \%$ was recorded at

322 high energy input $\left(32 \mathrm{kVcm}^{-1}\right)$. However, treatment of $P$. fluorescens with PEF was still

323 significantly less effective than pasteurisation $(P<0.05)$. The level of SLI of $P$.

324 fluorescens following treatment with PEF is illustrated in Figure 3(a). A larger

325 proportion of sub-lethally injured bacteria was observed at higher electric field intensity

326 (7.6\% for PEF-H, in contrast with $2.3 \%$ for PEF-L; $P<0.05$ ).

327 It was reported by Barbosa-Cánovas and Sepúlveda (2005) that the only factors

328 that have any significant impact on the functionality of PEF in microbial inactivation

329 are electric field intensity and residence time. The results in Figure 3(a) are in

330 agreement with this, as a significant $(P<0.05)$ difference in microbial inactivation was

331 observed as electric field intensity increased from the PEF-L to PEF-H. It was also

332 suggested that in order for PEF to result in any microbial inactivation at all, a minimum

333 threshold of field intensity must be applied, otherwise the technology is not effective

334 (Barbosa-Cánovas \& Sepúlveda, 2005).

335 It has been reported that studies conducted with mild temperature treatments are 
more effective than those performed at room temperature (Barbosa-Cánovas \&

337 Sepúlveda, 2005); this may have been a potential factor that led to the lower levels of $P$.

338 fluorescens inactivated, as the bacterial suspension was introduced into PEF at ambient

339 temperature. In the present study it was noted that the level of SLI increased with

340 electric field intensity $(P<0.05)$. Similar results were obtained by García, Gómez,

341 Manas et al. (2005) and Garcí, Gómez, Raso and Pagán (2005), where a higher

342 proportion of SLI of various species of bacteria was recovered as the field strength

343 increased. However, only a general assumption may be drawn as limited information

344 exists on P. fluorescens and how it behaves following PEF application.

345 Interestingly, E. coli was observed to have greater sensitivity to PEF, at all

346 electric field intensities when compared to $P$. fluorescens (Figure 3(b)). A substantial

347 reduction of $86.1 \%$ was noted following PEF-H treatment, which was significantly

348 higher than inactivation achieved at PEF-L, but not significantly different from thermal

349 pasteurisation at the 5\% significance level. While treatment with PEF-L $\left(29 \mathrm{kVcm}^{-1}\right)$

350 was significantly $(P>0.05)$ less effective than pasteurisation, this non-thermal

351 processing method demonstrated an impressive level of microbial inactivation as a

352 stand-alone technology. An inactivation level of 32.3\% was observed following PEF-L

353 treatment, while a reduction of $86.1 \%$ was recorded following treatment with PEF-H. A

354 less notable increase in inactivation was observed from low to high field intensity

355 application for $P$. fluorescens when compared to the results obtained for $E$. coli,

356 suggesting that E. coli is more susceptible to PEF processing.

357 The levels of sub-lethally injured E. coli cells following treatment with PEF are

358 also shown in Figure 3(b). The highest level of SLI was observed at the lowest energy

359 input, concurring that the levels of SLI were reduced with increasing electric field

360 intensity. This indicates that of the $32.3 \%$ and $86.1 \%$ of the population of $E$. coli killed

361 following treatment with PEF-L and PEF-H, respectively, 29.3\% and 4\% of those 
bacteria were only sub-lethally injured, respectively.

The results presented in Figure 3 (b) correlate well with a similar study

364 conducted by Aronsson et al. (2004), where it was reported that the level of inactivation

365 of E. coli increased with increasing electric field intensity. The results of the present

366 study may be in agreement with the theory of Barbosa-Cánovas and Sepúlveda (2005),

367 i.e. that it is necessary for a critical electrical field strength to be applied in order for

368 treatment with PEF to be efficient. This is evident with the vast differences between the

369 percentage killed following treatment with PEF-L and PEF-H, suggesting that a lower

370 field intensity of $29 \mathrm{kVcm}^{-1}$ only achieved a certain degree of microbial inactivation,

371 while leaving a greater proportion of cells injured.

372 The results observed in the present study for inactivation of E. coli following

373 treatment with PEF may offer some value to the food processing industry, as E. coli is a

374 potential safety hazard in beverages such as milk. The possible use of PEF processing as

375 a hurdle technology to combat E. coli contamination may be worthy of consideration

376 (Awuah et al., 2005). Further studies should be conducted to assess the inactivation

377 ability of PEF when used at a higher inlet temperature, as there have been some positive

378 reports of this effect (Barbosa-Cánovas \& Sepúlveda, 2005).

379 In a study conducted by García et al. (2005) and García, Gómez, Raso et al.

380 (2005), the highest proportion of sub-lethally injured E. coli cells were recorded

381 following PEF treatment at $19 \mathrm{kVcm}^{-1}$, with the numbers decreasing at $25 \mathrm{kV} \mathrm{cm}^{-1}$. It

382 was reported by García Gómez, Manas et al. (2005) and García, Gómez, Raso et al.

383 (2005) that due to the sensitivity of E. coli to PEF, the population of dead cells increased

384 with increasing electric field intensity, while the proportion of sub-lethally injured cells

385 decreased at higher electric field intensities. The results in Figure 3(b) are in agreement

386 with the findings of García, Gómez, Manas et al. (2005) and García, Gómez, Raso et al.

387 (2005). Although there were variations in proportions of sub-lethally injured E. coli 
388 between electrical field intensities (i.e. $29 \mathrm{kVcm}^{-1}$ and $32 \mathrm{kVcm}^{-1}$ ), no significant 389 differences were determined $(P>0.05)$. This is not surprising considering the difference 390 between the energy inputs was not that large.

391 Further investigation may be required in order to assess the application of PEF 392 processing when higher field intensity is applied, as favourable results have been 393 observed in previous studies (Alvarez et al., 2003). From the results of the present study,

394 it can be concluded that PEF processing is not an all or nothing event (Wu, 2008) and 395 that there was some evidence of SLI following the application of PEF. Interestingly, 396 there was no significant difference found between inactivation levels of $E$. coli 397 following treatment with PEF at $32 \mathrm{kVcm}^{-1}$ and pasteurisation $(P>0.05)$.

$399 \quad 3.3$ Effect of TS and PEF processing (combined) on microbial viability

400 Four combinations of TS/PEF were used to treat both E. coli and P. fluorescens; referred 401 to as LL, LH, HL, HH. The results of microbial inactivation and SLI, of P. fluorescens 402 following these treatments are shown in Figure 4(a). No significant difference was 403 observed between the power combinations used $(P>0.05)$ for results quantifying both 404 kill and SLI for this microorganism.

405 It has been suggested that a synergistic effect may be observed with the 406 application of TS and PEF combined (Noci et al., 2009) and that the cell damage caused 407 by one technology may increase the effects of the second technology. Such reports of 408 synergistic effects may be of benefit to the food and beverage industry. For instance, the 409 microbial inactivation achieved by TS alone is incomparable to the total bacterial kill 410 following traditional pasteurisation, yet treatment with PEF alone appears to be quite 411 effective. A publication by Noci et al. (2009) suggested that if the first hurdle 412 mechanism provides a weaker effect in terms of its inactivation, then inevitably it is 413 leaving a greater number of microorganisms to be inactivated by the second hurdle. This 
414 could be relevant in the present study, as due to the poor inactivation levels observed

415 following treatment with TS, it is therefore leaving a large quantity of microorganisms 416 to be inactivated by PEF.

417 A possible explanation for the lower inactivation observed at higher TS power 418 settings may be attributed to the fact that sonication may increase the availability of 419 nutrients, and that nutrients may become more abundant at higher TS levels (Piyasena et 420 al., 2003). In the present study the same residence times were used for low and high 421 amplitudes. This may have been a factor that led to the decline in inactivation at higher 422 amplitudes, in the treatments using (i) TS alone and (ii) TS/PEF combined. However, it 423 should be taken into consideration that different trends were observed between the 424 inactivation levels achieved using TS-L and TS-H for E. coli and P. fluorescens, as 425 significant differences $(P<0.05)$ were observed between the low and high energy inputs 426 for inactivation of $P$. fluorescens, but not for $E$. coli. From the results presented in 427 Figure 4(a) it could be suggested that, with regard to the inactivation of $P$. fluorescens, 428 PEF operates at its optimum at higher electric field intensities. The levels of microbial 429 inactivation obtained following TS/PEF processing were significantly less than thermal 430 pasteurisation $(P<0.05)$. This may be due to the ability of Pseudomonas to survive well 431 and to adapt to stressful environments. A study conducted by Lu et al. (2011) where $P$. 432 aeruginosa was subjected to cold stress reported that this microorganism was able to 433 survive well in environmental stress, with only a $3.1 \log$ CFU/ml reduction observed 434 when stored at $-18^{\circ} \mathrm{C}$. Although a direct comparison cannot be made between the 435 results reported by Lu et al. (2011) for inactivation resulting from frozen storage and the 436 present study where inactivation following treatment with high voltage PEF was 437 described, it is possible that $P$. fluorescens may be capable of surviving adverse 438 conditions, similar to the way P. aeruginosa can withstand challenging conditions. Even 439 though the TS/PEF treatment inactivated a low level of microbes, in general it achieved 
440 more inactivation than either technology used alone. Interestingly, for $P$. fluorescens, no

441 significant difference in SLI levels were detected between PEF alone and TS/PEF $442(P>0.05)$.

443 The results for microbial inactivation of $E$. coli following TS/PEF treatments 444 combined are illustrated in Figure 4(b). Similar to $P$. fluorescens, there was no 445 significant difference observed for inactivation or SLI at any of the power combinations

446 for $E$. coli $(P>0.05)$. From the results described here, it could be suggested that $E$. coli 447 is more sensitive to TS/PEF processing than $P$. fluorescens. Although considerable 448 levels of inactivation following treatment with TS/PEF were observed (71\% at $\mathrm{HH})$, 449 PEF-H treatment was found to achieve greater inactivation, with an average kill of 450 86.1\% observed. The capability of PEF to inactivate E. coli, when used at low field 451 intensities, was increased when combined with TS. The inactivation increased from $45232.3 \%$ at PEF-L, to between $62.6 \%$ and $71.5 \%$, when TS/PEF were used in 453 combination.

454 The highest quantity of SLI was observed at low electric field intensities of PEF 455 (i.e. $29 \mathrm{kV} \mathrm{cm}^{-1}$ ), $\mathrm{LL}$ (25.5\%) and $\mathrm{HL}$ (24.9\%). Inactivation due to thermal 456 pasteurisation was significantly greater $(P<0.05)$ than inactivation following TS/PEF 457 combined processing of E. coli, although an impressive inactivation level was obtained 458 for the HH combination (71.5\%).

459 It is possible that TS did not have a vast impact on the inactivation of E. coli 460 when used at high power combinations such as $\mathrm{HH}$, as it has been suggested by 461 Piyasena et al. (2003) that the intensity of TS does not largely effect the amount of 462 inactivation of E. coli, and that the majority of inactivation may have been attributed to 463 PEF. However, it is plausible that TS weakened the cell membrane of the bacteria 464 (Barbosa-Cánovas \& Sepúlveda, 2005) and that the weakened cell was compromised 465 thus becoming more susceptible to PEF. Despite the report by Piyasena et al. (2003), it 
was observed that TS did, in fact, have beneficial effects on the performance of PEF at

467 low field intensities, increasing the percentage killed from 32.3\% when PEF-L was

468 applied alone, to $62.6 \%$ (LL) and $64.8 \%$ at (LH).

469

$470 \quad$ 3.4. Bacterial growth monitoring using optical density

471 It is evident from Figure 5(a) that the growth of E. coli was not vastly affected by 472 treatment with TS at either the high or low energy input $(19 \mu \mathrm{m}$ and $28 \mu \mathrm{m}$, 473 respectively) when compared to control growth. However, E. coli cells treated with L 474 and $\mathrm{H}$ power outputs took slightly longer to enter the log phase (c. $1 \mathrm{~h})$. It appears from 475 Figure 5(a) that very low levels of sub-lethally injured E. coli were present, which is in 476 agreement with the results presented in Figure 2(b).

$477 \quad$ Following treatment with PEF, it was evident that cells treated at PEF-L entered 478 the log phase more rapidly than E. coli treated at PEF-H, where it took approximately 7 $479 \mathrm{~h}$ and $12 \mathrm{~h}$, respectively, to enter the log phase (Figure 5b). These results suggesting SLI 480 correlate quite well to the findings presented in Figure 3(b). The growth curves for E. coli following treatment with TS/PEF combined are 482 shown in Figure 5(c). The level of SLI is clearly evident, as it took each E. coli culture 483 (following treatment with $\mathrm{TS} / \mathrm{PEF}$ ) at least $12 \mathrm{~h}$ to enter the log phase. This 484 demonstrates SLI, and confirms the results presented in Figure 4(b). Thus, there 485 appeared to be agreement between the results obtained from the OD-based method 486 (Figures 5a-5c) and the crude plating technique (Figures 2b, 3b, 4b).

\section{Conclusion}

489 In conclusion, it was established that TS treatment alone was not an effective method 490 for the inactivation of P. fluorescens and E. coli. Also, this study has shown the potential 491 of PEF for effective inactivation of E. coli, with less favourable results obtained for $P$. 
492 fluorescens. However, TS/PEF combined proved to be substantially more effective with 493 regard to microbial inactivation of E. coli than when applied to P. fluorescens.

494 SLI was observed following the majority of treatments, with substantial levels of 495 injury evident when TS/PEF were applied for both $P$. fluorescens and E. coli. A future 496 challenge may be to focus on eliminating this population of sub-lethally injured 497 bacteria.

498

\section{Acknowledgements}

500 This work was carried out using equipment purchased by SMARTMILK, a 2 year R\&D

501 project funded by the Seventh Framework Programme of the EC under the "Research

502 for SMEs” sub-programme. Grant agreement No. 261591.

503

504

505

506

507

508

509

510

511

512

513

514

515

516

517 


\section{Literature cited}

519 Alvarez, I., Virto, R., Raso, J. \& Condón, S. (2003). Comparing predicting models for the Escherichia coli inactivation by pulsed electric fields. Innovative Food Science \& Emerging Technologies, 4 (2), 195-202.

522 Aronsson, K., Borch, E., Stenlöf, B., \& Ronner, U. (2004). Growth of pulsed electric field exposed Escherichia coli in relation to inactivation and environmental factors. International Journal of Food Microbiology, 93 (1), 1-10.

525 Awuah, G.B., Ramaswamy, H. S., Economides, A., \& Mallikarjunan K. (2005). Inactivation of Escherichia coli K-12 and Listeria innocua in milk using radio

Barsotti, L. \& Cheftel, J.C. (1999). Food processing by pulsed electric fields. II. Biological aspects. Food Reviews International, 15 (2), 181-213.

534 Black, E. P., Kelly, A. L., \& Fitzgerald, G. F. (2005). The combined effect of high pressure and nisin on inactivation of microorganisms in milk. Innovative Food Science \& Emerging Technologies, 6 (3), 286-292.

Caminiti, I.M., Noci, F., Munoz, A., Whyte, P., Morgan, D.J., Cronin, D.A., \& Lyng, J.G. (2011) Impact of selected combinations of non-thermal processing technologies on the quality of an apple and cranberry juice blend. Food

541 Condón, S., Raso, J., \& Pagán, R. (2005). Microbial Inactivation by Ultrasound. In G.

542 V. Barbosa-Canovas, M. S. Tapia, \& M. P. Cano (Eds) Novel food processing technologies (Chapter 19). Boca Raton, USA: CRC Press. 
544 Dobrindt, U. (2005). (Patho-) Genomics of Escherichia coli. International Journal of $545 \quad$ Medical Microbiology, 295 (6-7), 357-371.

546 García, D., Gómez, N., Raso, J., \& Pagán, R. (2005). Bacterial resistance after pulsed electric fields depending on the treatment medium $\mathrm{pH}$. Innovative Food Science \& Emerging Technologies, 6 (4), 388-395.

549 García, D., Gómez, N., Manas, P., Condón, S., Raso, J., \& Pagán, R. (2005). Occurrence of sublethal injury after pulsed electric fields depending on the micro-organism,

Hamilton W.A., \& Sale, A.J.H. (1967) Effects of high electric fields on microorganisms. II. Mechanism of action of the lethal effect. Biochimica et Biophysica Acta, 87,

Jaeger, H., Schulz, A., Karapetkov, N., \& Knorr, D. (2009). Protective effect of milk 102-107

Jatzwauk, L., Schöne, H., \& Pietsch, H. (2001) How to improve instrument disinfection by ultrasound. The Journal of Hospital Infection, 48, Supplement A, S80-S83.

Lu, X., Liu, Q., Wu, D., Al-Qadiri, H. M., Al-Alami, N. I., Kang, D-H, Shin, J-H., Tang, Limaye, M. S. \& Coakley, W. T. (1998) Clarification of small volume microbial J., Jabal, J. M. F., Aston, E. D., \& Rasco B. A. (2011) Using of infrared spectroscopy to study the survival and injury of Escherichia coli O157:H7, Campylobacter jejuni and Pseudomonas aeruginosa under cold stress in low nutrient media. Food Microbiology, 28 (3), 537-546. 
570 Noci, F., Walkling-Ribeiro. M., Cronin, D. A., Morgan, D. J., \& Lyng, J. G. (2009). Effect of thermosonication, pulsed electric field and their combination on inactivation of Listeria innocua in milk. International Dairy Journal, 19 (1), 3035.

574 Perni S., Chalise P. R., Shama, G., \& Kong, M. G. (2007). Bacterial cells exposed to nanosecond pulsed electric fields show lethal and sublethal effects. International Journal of Food Microbiology, 120 (3), 311-314.

Piyasena, P., Mohareb, E., \& McKellar, R.C. (2003). Inactivation of microbes using

Raso, J., Pagán, R., \& Condón, S. (2005). Nonthermal technologies in combination with other 581 preservation factors. In G. V. Barbosa-Canovas, M. S. Tapia, \& M. P. Cano (Eds.), Novel food processing technologies (Chapter 21). Boca Raton, USA: CRC Press.

583 Ross, A. I. V., Griffiths, M. W., Mittal, G. S., \& Deeth, H. C. (2003). Combining nonthermal technologies to control foodborne microorganisms. International Journal of Food Microbiology, 89 (2-3), 125-138.

Scherba, G., Weigel, R. M., \& O’Brien, W. D. (1991). Quantitative assessment of the germicidal efficacy of ultrasonic energy. Applied and Environmental Microbiology, 57 (7), 2079-2084.

Shamsi, K., Versteeg, C., Sherkat, F., \& Wan, J. (1997) Alkaline phosphatase and microbial inactivation by pulsed electric field in bovine milk. Innovative Food

592 Sillankorva, S., Neubauer, P., \& Azeredo, J. (2008) Pseudomonas fluorescens biofilms 593 subjected to phage phiIBB-PF7A. BMC Biotechnology, 8, 79-91.

594 Uyttendaele, M., Rajkovic, A., Van Houteghem, N., Boon, N., Thas, O., Debevere, J., \& Devlieghere, F. (2008). Multi-method approach indicates no presence of sub- 

lethally injured Listeria monocytogenes cells after mild heat treatment. International Journal of Food Microbiology, 123 (3), 262-268.

598 Villamiel, M. \& de Jong, P. (2000) Inactivation of Pseudomonas fluorescens and 599 Streptococcus thermophilus in Trypticase ${ }^{\circledR}$ Soy Broth and total bacteria in milk 600 by continuous-flow ultrasonic treatment and conventional heating. Journal of $601 \quad$ Food Engineering, 45 (3), 171-179.

602 Walkling-Ribeiro, M., Noci, F., Cronin, D. A., Lyng, J. G., \& Morgan, D. J. 603 (2008). Inactivation of Escherichia coli in a tropical fruit smoothie by a 604 combination of heat and pulsed electric fields. Journal of Food Science, 73 (8), 605 M395-M399.

606 Wu, V.C.H. (2008) A review of microbial injury and recovery methods in food. Food $607 \quad$ Microbiology, 25 (6), 735-744.

608 Xu, J., Bigelow, T. A., Halverson, L. J., Middendorf, J. M., \& Rusk, B. (2012) 609 Minimization of treatment time for in vitro $1.1 \mathrm{MHz}$ destruction of 610 Pseudomonas aeruginosa biofilms by high-intensity focused ultrasound. 611 Ultrasonics, 52, (5), 668-675.

612 Zhao, W., Yang, R., Shen, X., Zhang, S., \& Chen, X. (2013) Lethal and sublethal injury 613 and kinetics of Escherichia coli, Listeria monocytogenes and Staphylococcus 614 aureus in milk by pulsed electric fields. Food Control, 32 (6), 6-12. 


\section{List of Figures:}

Figure 1: Schematic diagrams of laboratory scale (a) thermosonication and (b) pulsed electric field treatment chamber systems used in this study.

Figure 2: Levels of (a) P. fluorescens and (b) E. coli killed ( $\square$ ) and sub--lethally injured ( $\square$ ) following treatment with thermosonication at low (TS-L; $19 \mu \mathrm{m})$ and high (TS-H; $28 \mu \mathrm{m})$ energy inputs and thermal pasteurisation. (Data= mean \pm S.D., $n=2$ ). Values for $100 \%$ viability were $8.6 \times 10^{8} \mathrm{CFU} / \mathrm{ml}$ and $6.1 \times 10^{8} \mathrm{CFU} / \mathrm{ml}$ for $P$. fluorescens and $E$. coli, respectively.

Figure 3: Levels of (a) P. fluorescens and (b) E. coli killed (ロ) and sub-lethally injured ( $\square$ ) following treatment with pulsed electric fields (PEF) at low (PEF-L; $29 \mathrm{kVcm}^{-1}$ ) and high (PEF-H; $32 \mathrm{kVcm}^{-1}$ ) power intensities and thermal pasteurisation. (Data= mean \pm S.D., $\mathrm{n}=2$ ). Values for $100 \%$ viability were $8.6 \times 10^{8} \mathrm{CFU} / \mathrm{ml}$ and $6.1 \times 10^{8} \mathrm{CFU} / \mathrm{ml}$ for $P$. fluorescens and E. coli, respectively.

Figure 4: Levels of (a) P. fluorescens and (b) E. coli killed (ロ) and sub-lethally injured ( $\square$ ) following combined treatment with thermosonication (TS) and pulsed electric fields (PEF) and thermal pasteurisation. Treatmens of TS/PEF were as follows; LL (19 $\left.\mu \mathrm{m}, 29 \mathrm{kVcm}^{-1}\right)$, LH $\left(19 \mu \mathrm{m}, 32 \mathrm{kVcm}^{-1}\right)$, HL $\left(28 \mu \mathrm{m}, 29 \mathrm{kVcm}^{-1}\right)$ and HH $\left(28 \mu \mathrm{m}, 32 \mathrm{kVcm}^{-1}\right)$. (Data= mean \pm S.D., $\mathrm{n}=2$ ). Values for $100 \%$ viability were $8.6 \times 10^{8} \mathrm{CFU} / \mathrm{ml}$ and $6.1 \times 10^{8} \mathrm{CFU} / \mathrm{ml}$ for $P$. fluorescens and E. coli, respectively.

Figure 5: (a) Standard curve of $\mathrm{OD}_{590}$ Vs. CFU/ml of E. coli, (b) effect of TS at $19 \mu \mathrm{m}$ (TS-L; $\left.\boldsymbol{\square}\right)$ and $28 \mu \mathrm{m}(\mathrm{TS}-\mathrm{H} ; \boldsymbol{\Delta})$ on growth of E. coli, (c) effect of PEF at $29 \mathrm{kV} \mathrm{cm}^{-1}$ (PEF-L) ( $\left.\mathbf{\square}\right)$ and $32 \mathrm{kV} \mathrm{cm}^{-1}$ (PEF-H; $\left.\boldsymbol{\Delta}\right)$ on growth of E. coli, and (d) effect of TS/PEF combined (LL;

LH; $\boldsymbol{\Delta}, \mathrm{HL} ; \square$ and HH; $\Delta$ ) on growth of E. coli. Control growth for E. coli $(\bullet)$ is included for comparison purposes. (Data= mean \pm S.D., $n=2$ ). 


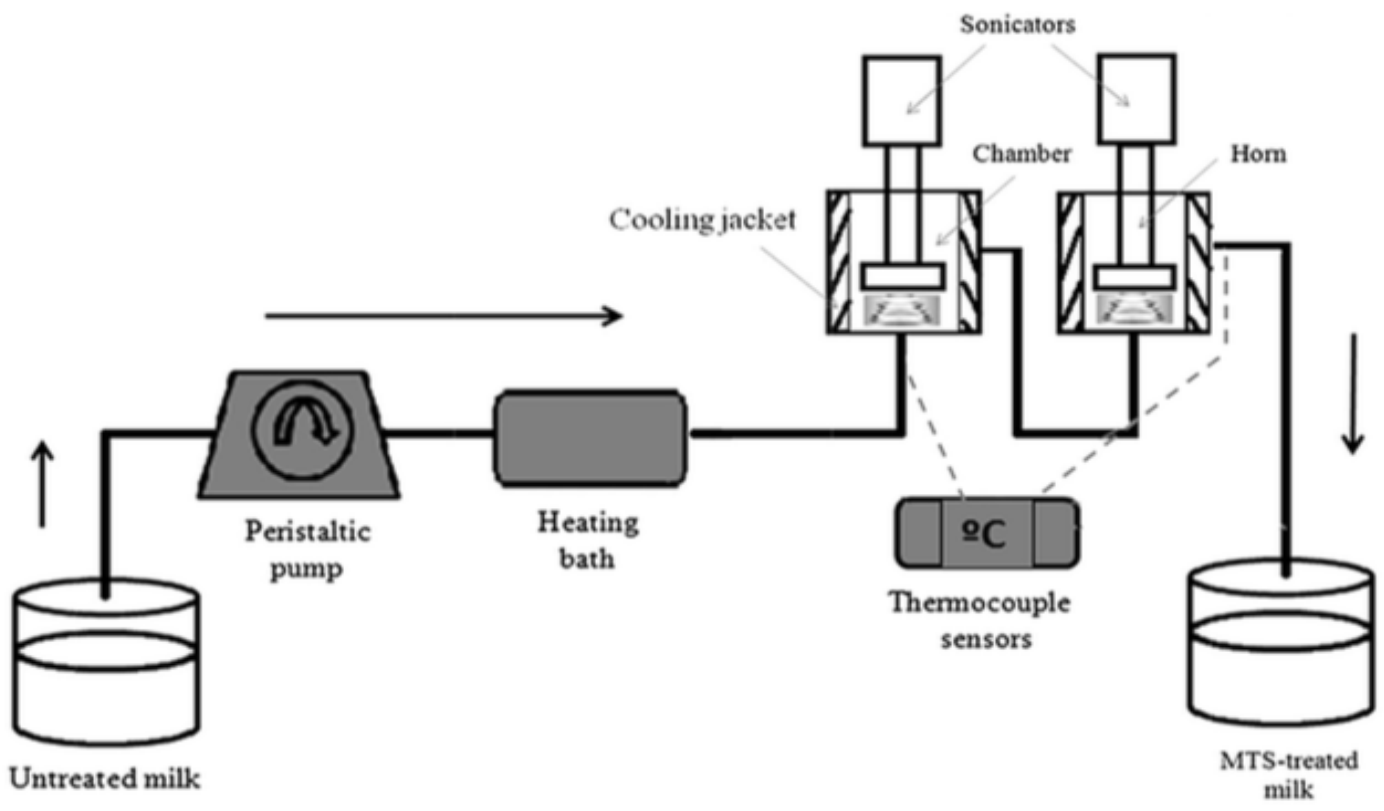

Untreated bacterial suspension

Figure 1 (a)

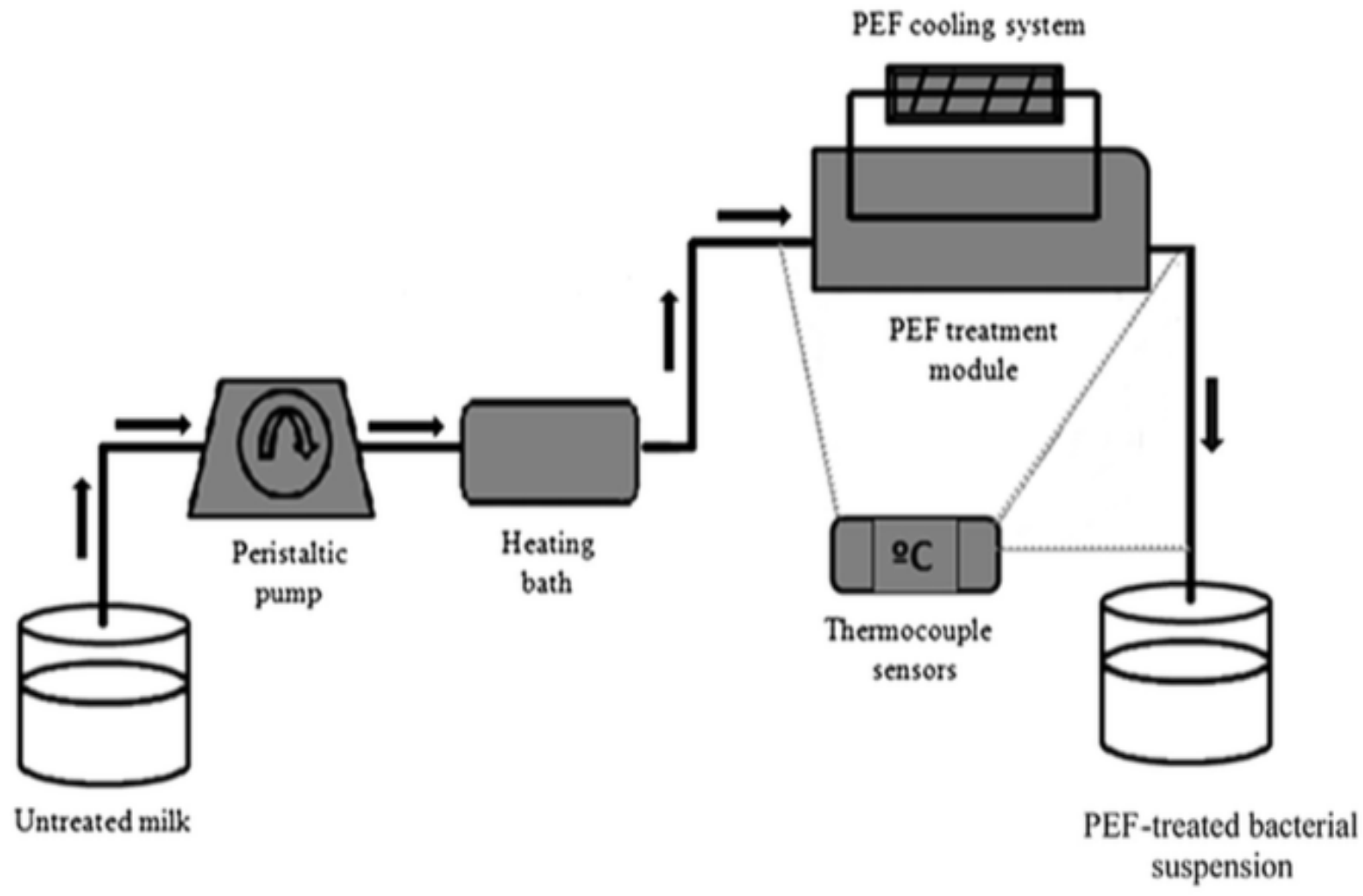

Figure 1 (b) 


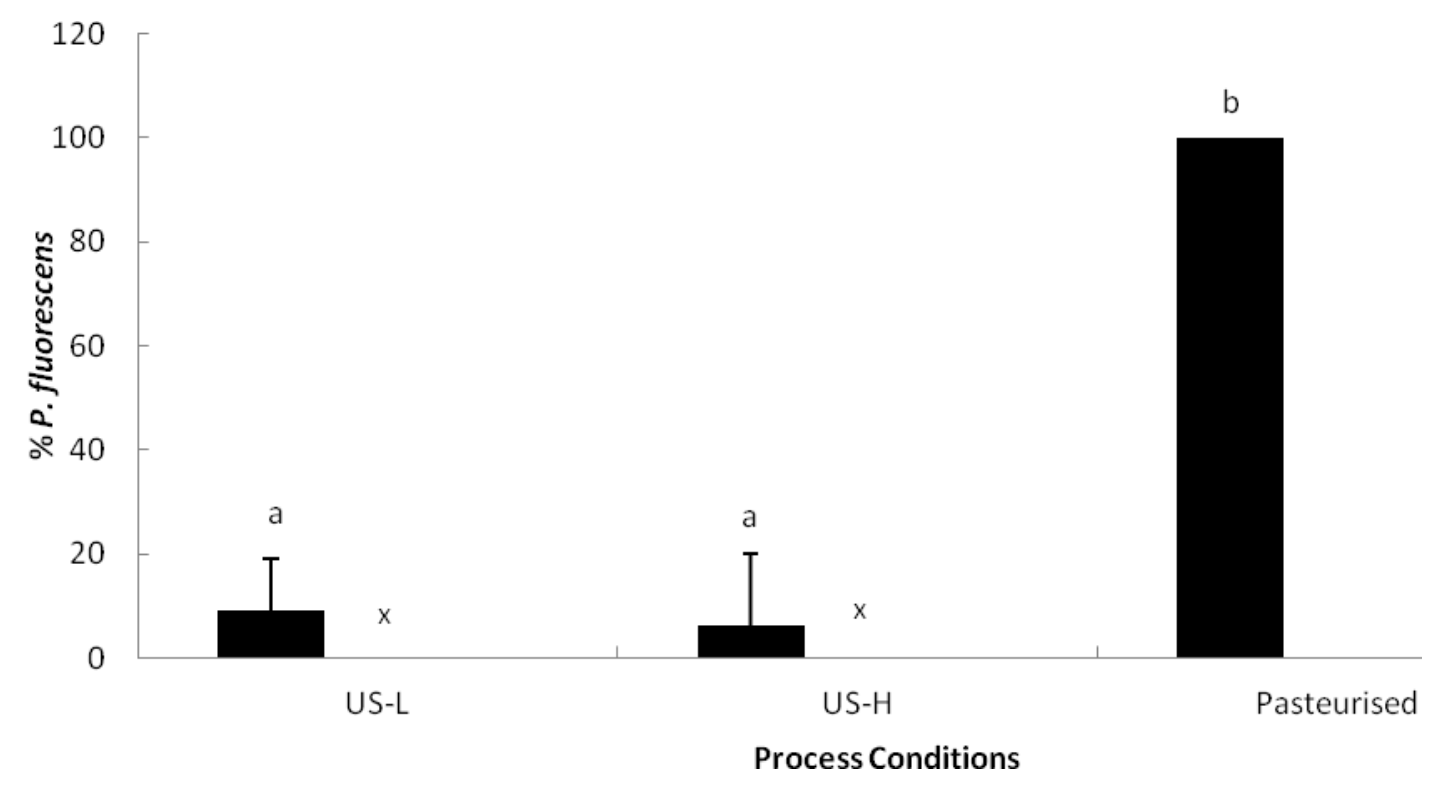

Figure 2 (a)

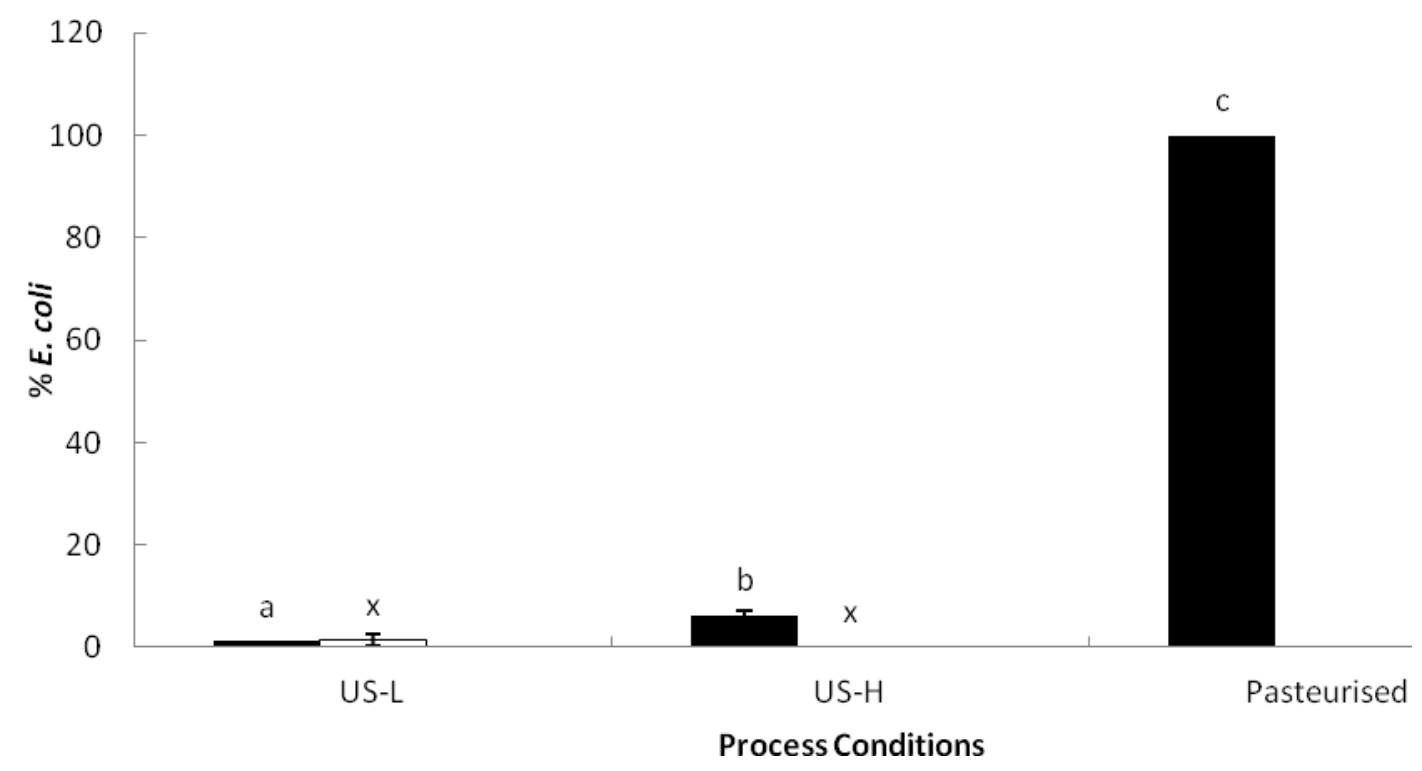

Figure 2 (b)

Footnote: Statistical differences (if any) between percentage killed are shown as a,b,c etc. while statistical differences (if any) between sub-lethal injury are shown as x,y,z etc. 


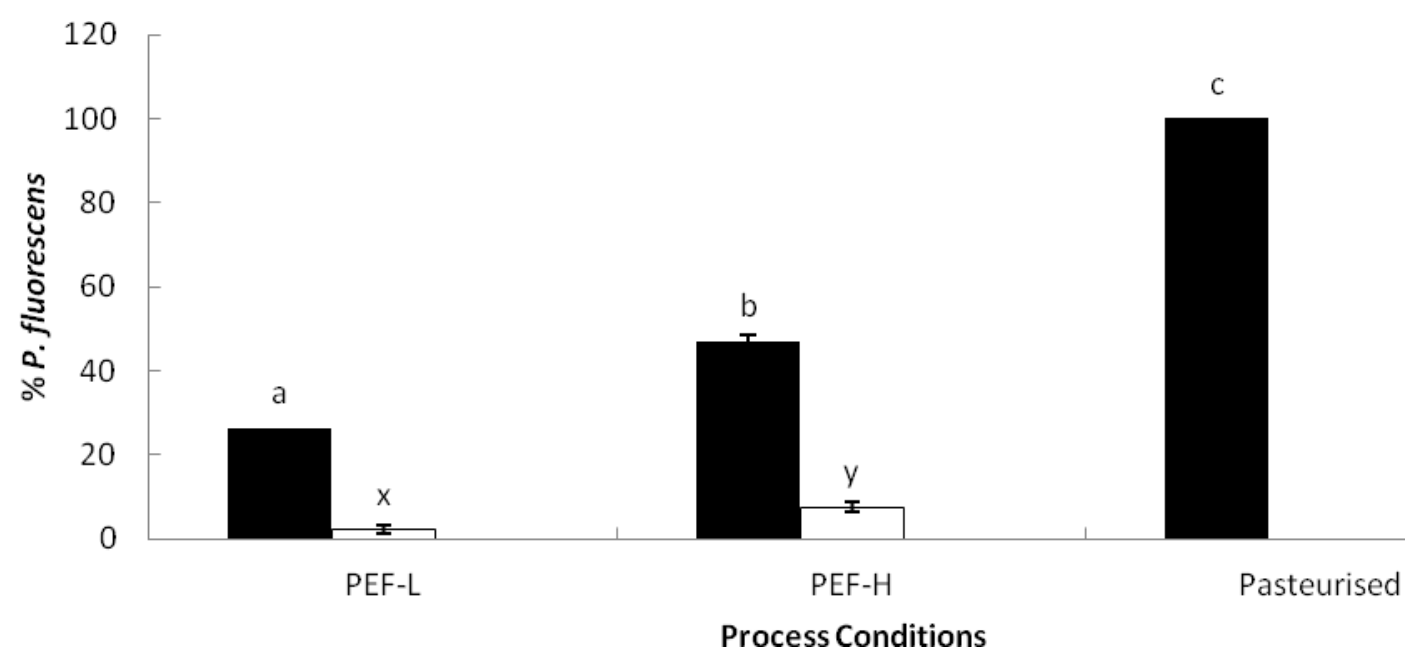

Figure $3(\mathrm{a})$

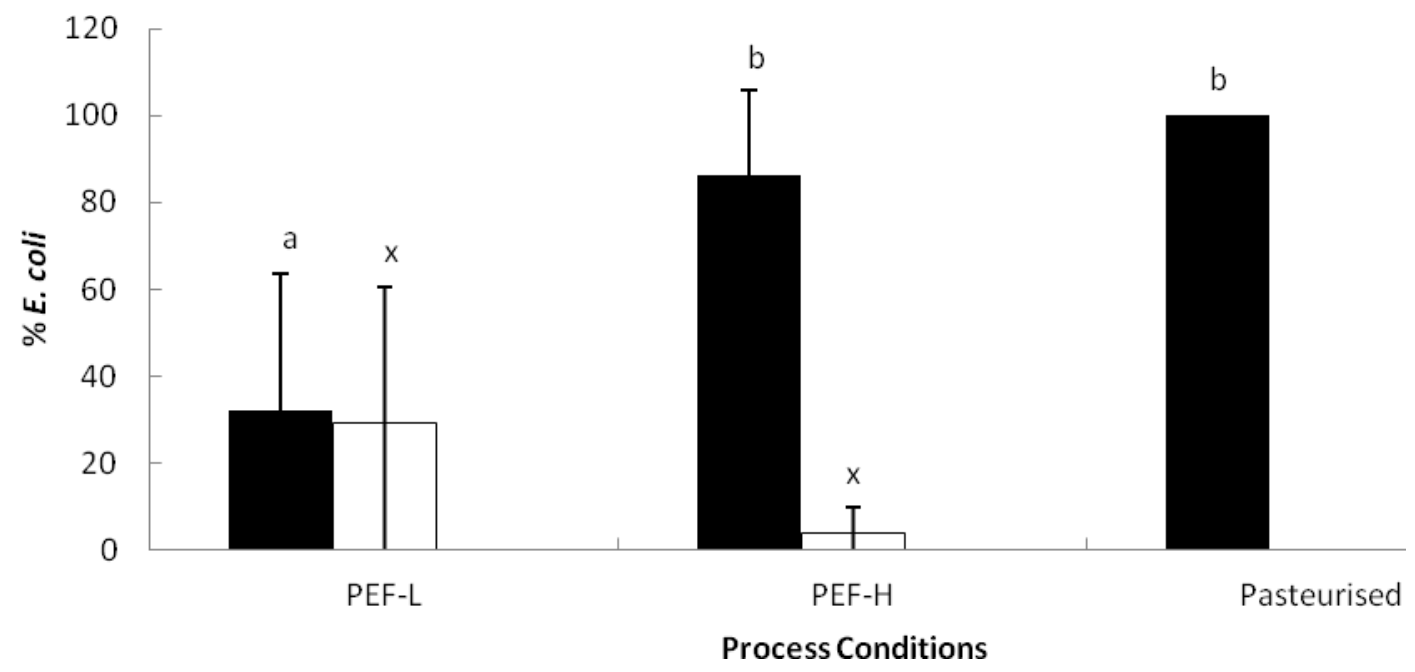

Figure 3 (b)

Footnote: Statistical differences (if any) between percentage killed are shown as a,b,c etc. while statistical differences (if any) between sub-lethal injury are shown as x,y,z etc. 


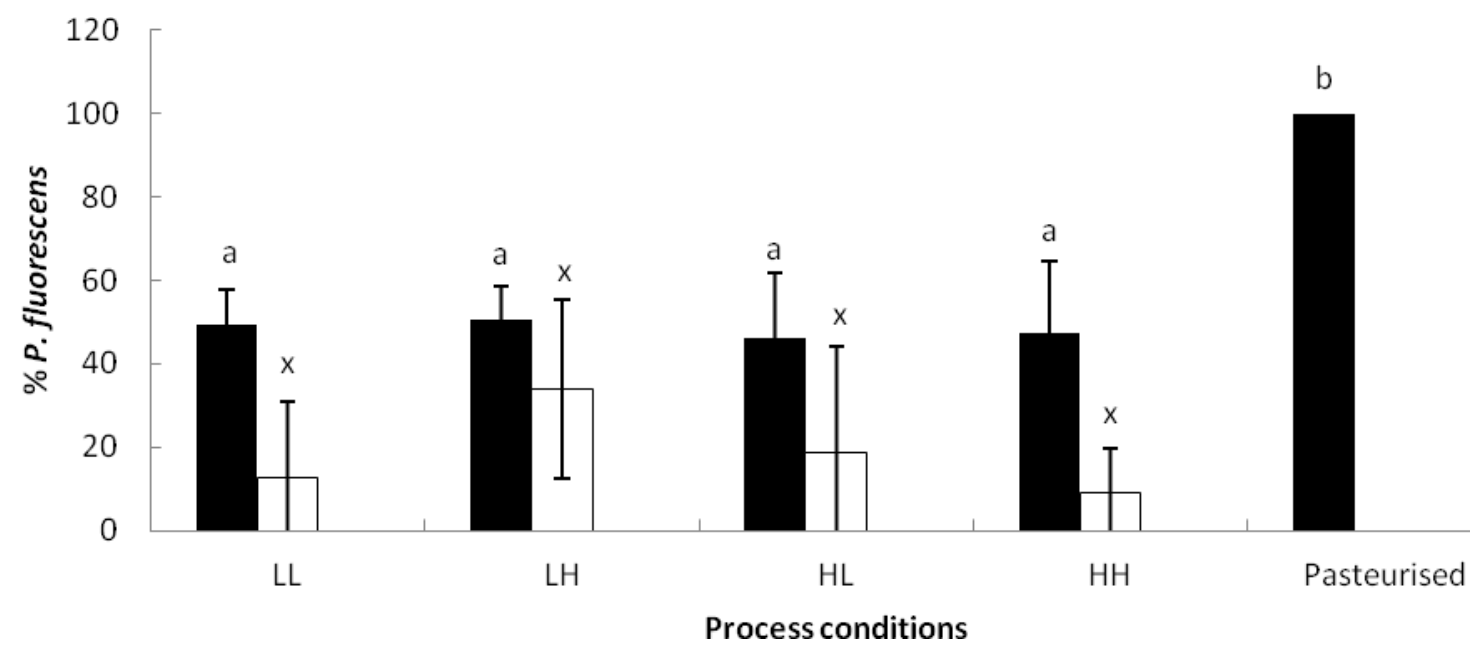

Figure 4 (a)

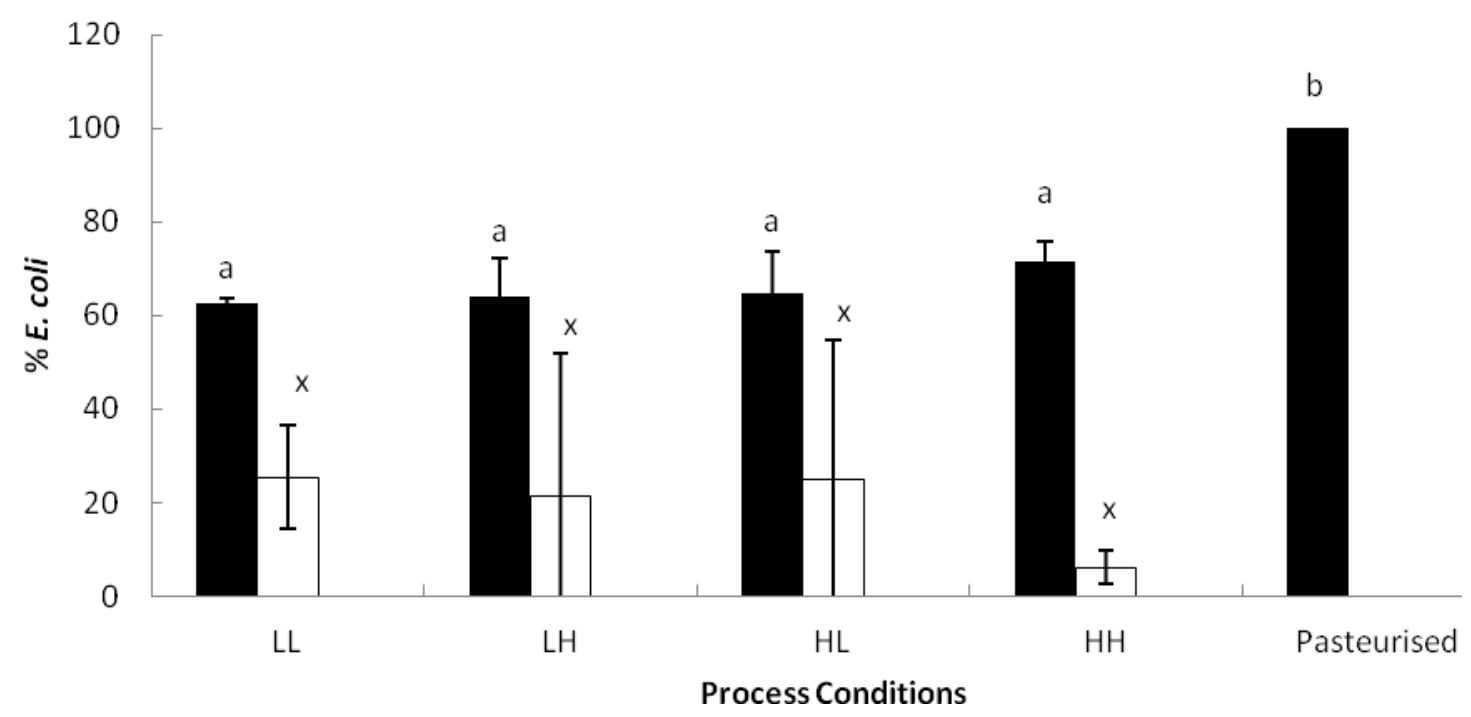

Figure 4 (b)

Footnote: Statistical differences (if any) between percentage killed are shown as a,b,c etc. while statistical differences (if any) between sub-lethal injury are shown as x,y,z etc. 


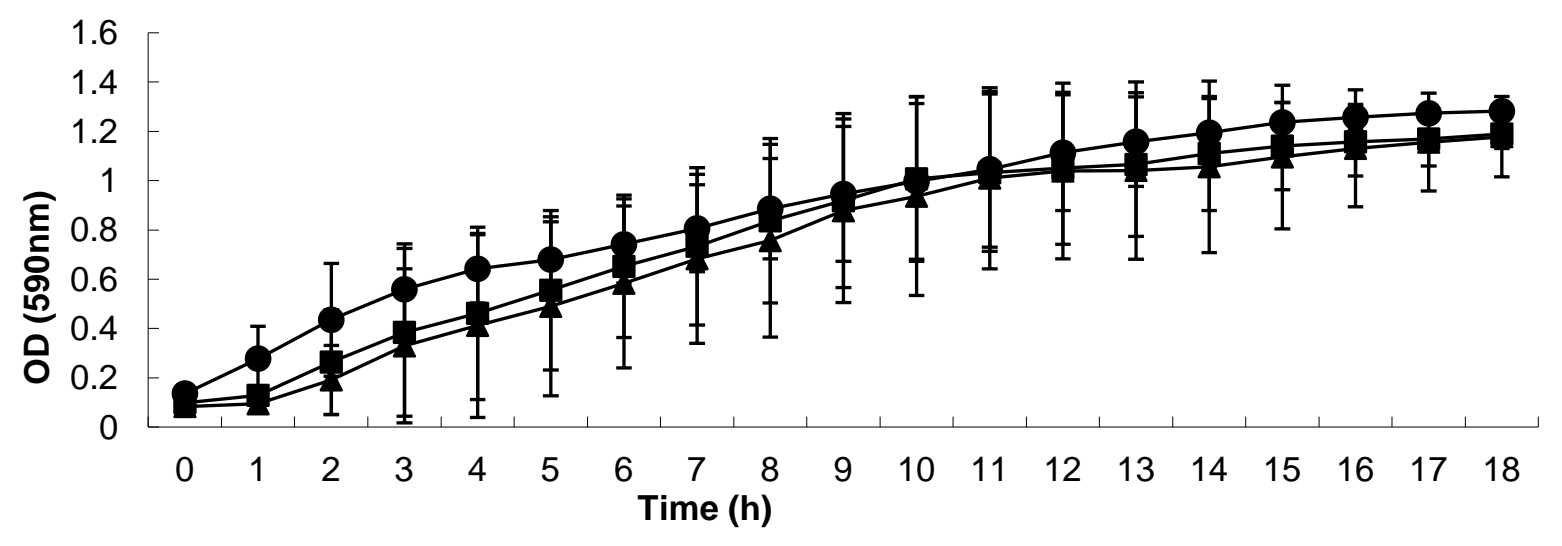

Figure 5 (a)

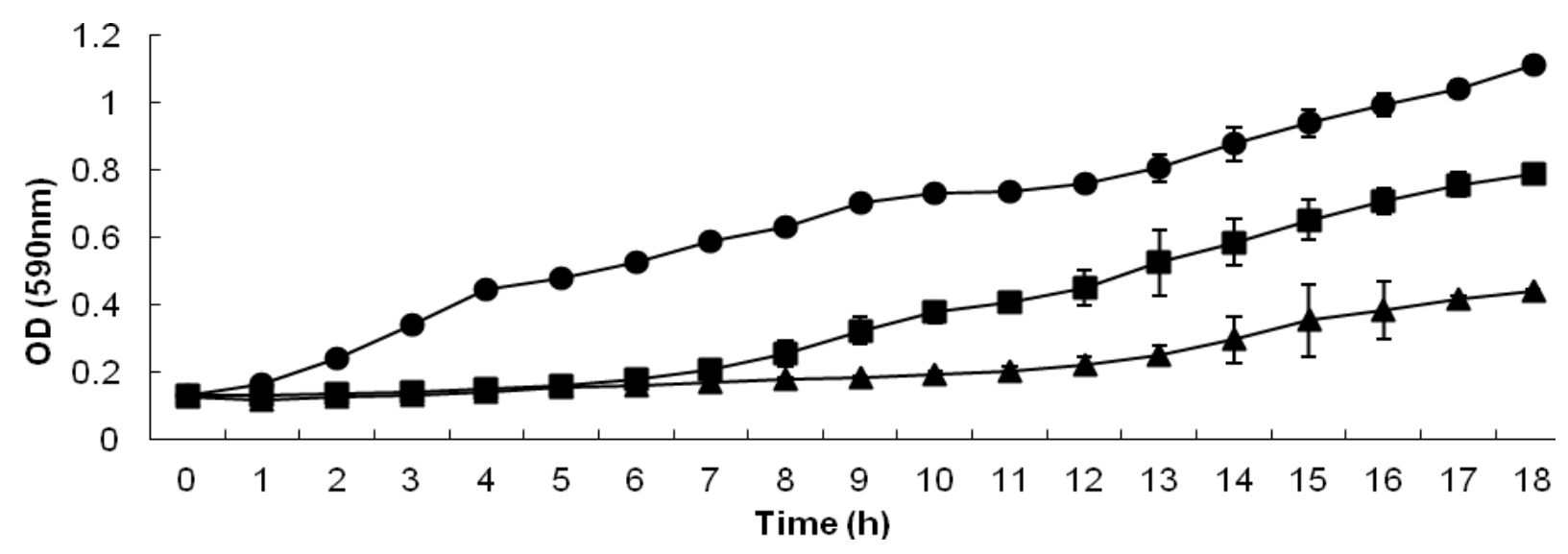

Figure 5 (b) 


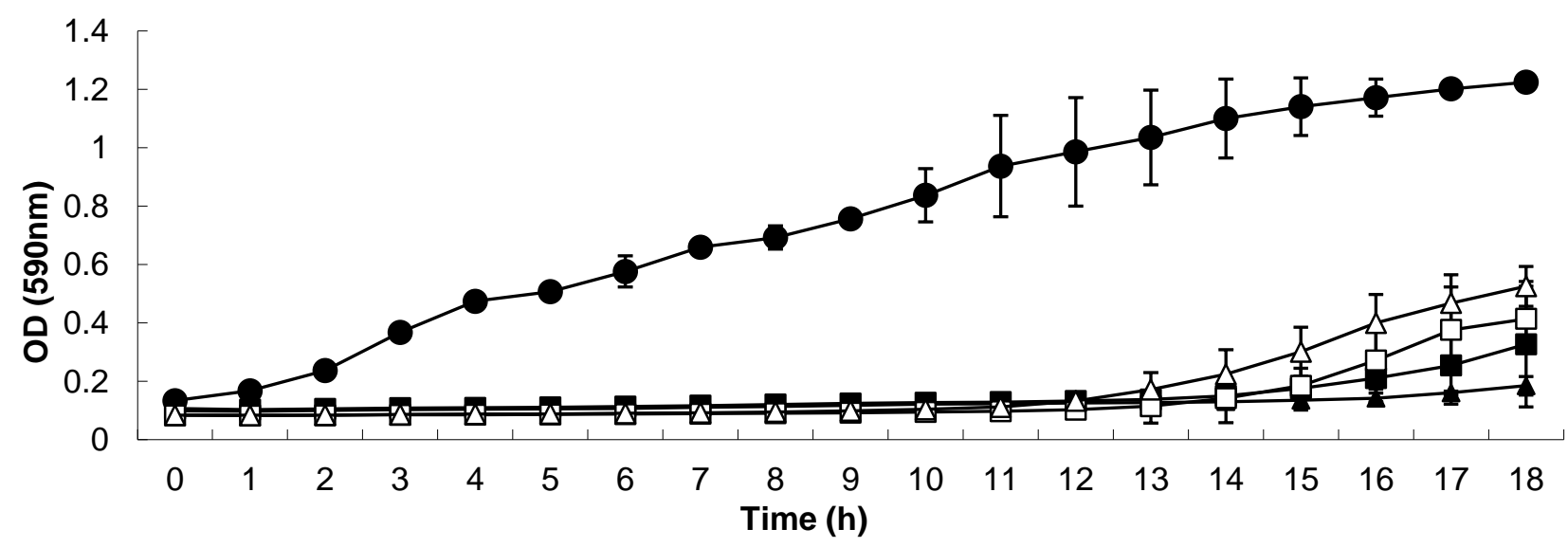

Figure 5 (c) 